International Journal of Engineering \& Technology, $7(3.12)(2018) 1312-1316$
International Journal of Engineering \& Technology
SPC
Website: www.sciencepubco.com/index.php/IJET
Research paper

\title{
A Review on Forest Fire Detection Techniques: A Decadal Perspective
}

\author{
Vinay Chowdary ${ }^{1}$, Mukul Kumar Gupta ${ }^{2}$, Rajesh Singh ${ }^{3}$ \\ ${ }^{1,2,3}$ Department of Electronics \& Instrumentation \\ University of Petroleum and Energy Studies, Dehradun, India \\ *Corresponding Author Email: ${ }^{1}$ vchowdary@ddn.upes.ac.in, ${ }^{2}$ mkgupta@ddn.upes.ac.in \\ ${ }^{3}$ rsingh@ddn.upes.ac.in
}

\begin{abstract}
Forest fire disasters have always been mankind's constant and inconvenient companion since time immemorial. In the recent past years, managing crisis for example a large scale fire has become a very difficult and challenging task. Things that are common in most of the forest fire that occur at large scale are loss of life (human or animal), loss of vegetation, loss of flora and fauna, and communication failure (if any). Apart from causing a great loss to valuable natural resources of nature forest fire pose a greater risk not only to life of human being but also to the inhabitant's such as wild life living in the forest. As per National Fire Danger Rating System (NFDRS), if a fire is detected within 6 minutes of its occurrence then it can be easily disposed-off before it turns into a large scale fire. For this a network that can detect fire at a very early stage is required. There are numerous techniques to detect the occurrence of forest fire and this article is dedicated towards reviewing detection techniques present in the literature. This work will give a bird's eye view of the technologies used in automatic detection of forest fires and reviews almost all the detection techniques available in the literature. To the best of our knowledge this is the first time that almost all the techniques available in the literature are reviewed and considering almost all the parameters.
\end{abstract}

Keywords: Forest Fire, Networks, Techniques.

\section{Introduction}

Forests are the main ecological balance contributor to the nature. Unfortunately, this ecological balance is greatly disturbed by fire disaster that occur regularly every year in every forest of every country. Every year thousands of hectares of forest land are destroyed by incidences of fire. This will generate much more Carbon Monoxide (CO) when compared to CO released by overall vehicular traffic. A known rule as mentioned in [1] applies here i.e., if a fire continues to burn for a minute then it can be disposedoff by one cup of water (say 1 litre) and if the burning time is doubled then the amount of water required will be multiplied by ten times. Similarly, a fire with a burning time of 10minutes may need more than 1000 litres of water. The main causes of forest fire almost every time are natural and man-made of which man-made causes are always on rise. Natural causes include fire due to lighting and lava and man-made causes range from unattended campfires, cigarettes that are discarded negligently, uncontrolled burning of debris to intentionally setting the forest on fire, the causes that are mostly common. The sad part of forest fires is that it can only be detected once it has spread and covered a considerable area. Once a fire covers a considerable portion of forest it always becomes uncontrollable and disposing off these fires is out of reach. The occurrence of fire in forest can be classified into three types as shown in Fig.1.

Ground fire generally produces only heat without much flames. Therefore, to detect these type of fires high precision sensor is required which are sensitive to detect changes in temperature of even $1^{\circ} \mathrm{C}$. Thermal and radiation sensors are sensitive to record changes as small as $1^{\circ} \mathrm{C}$ in temperature[2]. Also as given in [3] reptiles equipped with sensors can be used to detect ground fires. Surface fires generates smoke and will occur on the surface of the forest. There will not be much heat generated and neither flames are developed. Therefore, a smoke sensor will suffice the purpose of detecting surface fire. Crown fire generates heavy flames and is a result of surface fire going undetected. A surface fire if not disposed-off at its initial stage will take a shape of crown fire. No sensor will be able to withstand the high temperature generated by crown fire.

Rest of the paper is organised as follows

Section II gives the overview and comparison of different detection techniques available in the literature. Section III proposes architecture suitable for forest fire detection and section IV concludes the paper.

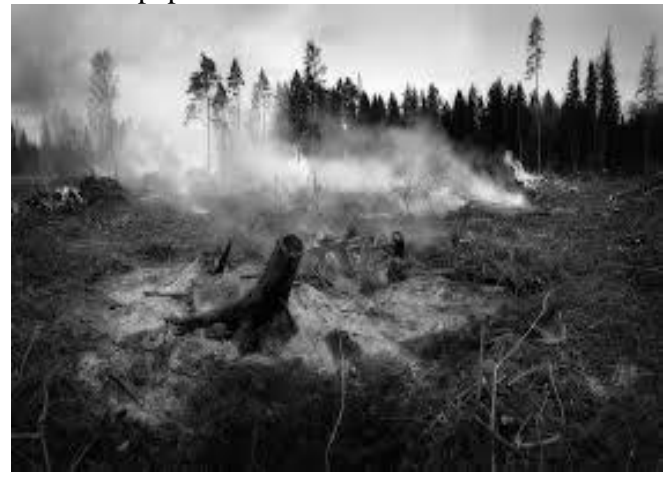

(a) Ground Fire 


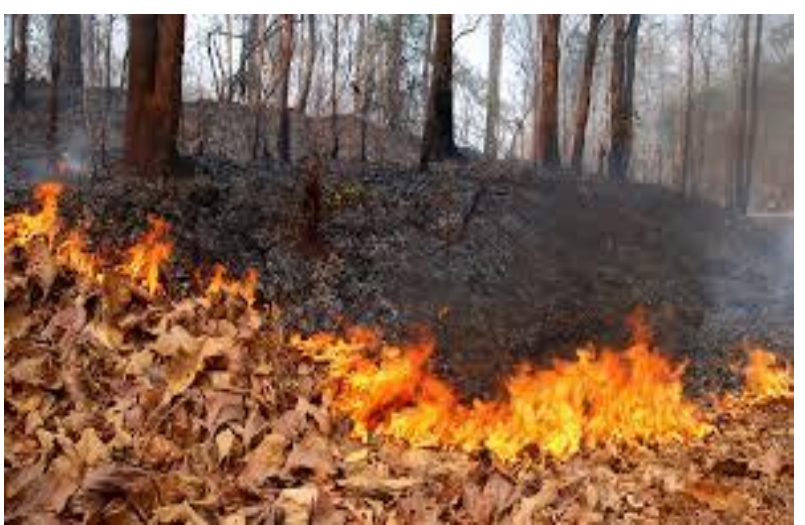

(b) Surface Fire

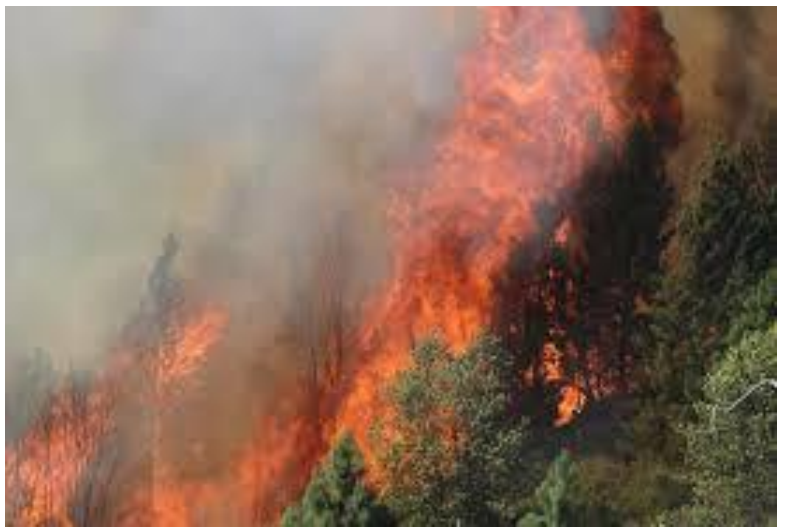

(c) Crown Fire

Fig. 1: Types of Forest Fire

Fig. 1a represents ground fire where the fire ignition happens below the ground and only smoke will be visible above the ground without any flames.

Fig. $1 \mathrm{~b}$ is for surface fire where the ignition happens because of leaves spread on the surface of forest. In this case flames are visible and also some smoke. The height of the flame at the initial stages of fire will be minimum and as the fire progresses the height of flame increases and the smoke density reduces. If the fire is not controlled in its initial phase, then within no time it converts into a crown fire.
Fig 1c is crown fire where the complete forest is burnt and the height of flames is visible from distance. Here the fire becomes uncontrollable and can only be disposed-off naturally.

\section{Forest Fire Detection Techniques}

There are many techniques used by the authorities to detect forest fires, satellite detection being the common amongst authorities of across the globe. Few authorities use human observers as detectors and reporters of forest fires. This section is detected towards discussing the different detection techniques available in the literature and also highlights the differences among all the techniques. Table I highlights the differences amongst them. Table II divides the number of references into year wise and technique wise. This division is performed on the basis of techniques available in the literature and considering the techniques available in the last decade. Parameters considered for comparison are generalized ones such as implementation cost of the system, the practicality of the system in real time scenario, discussion of the system in literature, whether the detection device is stationary or mobile, the mechanism of providing power to the detection device/ recharging, whether the system is providing the fire behaviour i.e., the fire spread information, whether the system is suitable for detection in a specified/limited region or can it cover the entire forest, the delay between detecting the fire incident and reporting it to the central node or control centre, rate of false alarms i.e., whether the system is capable of differentiating the exact occurrence of fire from the symptoms of fire, the error between the exact location point of fire to the point given by the system. These techniques can also be divided into a category that differentiates between hardware computing techniques and soft computing techniques. In hardware computing techniques the fire detection network should have a real time data which has to be collected by deploying the network in close to real time situations. The data collected will be in real time and analysis performed will also be in real time. In soft computing techniques the data on which analysis will be performed will not be of real time and therefore will have certain assumptions which may not be true. Also there are many techniques which are dependent on data coming from satellite images and these techniques will have a waiting period that ranges from 12 to 48 hours.

Table 1: Comparison Amongst Different Forest Fire Detection Techniques

\begin{tabular}{|c|c|c|c|c|c|c|c|c|}
\hline Comparison & $\begin{array}{c}\text { Sensor Based } \\
\text { Techniques } \\
\text { (Wireless } \\
\text { sensor } \\
\text { Networks) } \\
\text { [4-12] }\end{array}$ & $\begin{array}{c}\text { Camera } \\
\text { Based } \\
\text { Techniques } \\
\text { (Image and } \\
\text { Video } \\
\text { Processing) } \\
\text { [13-27] } \\
\end{array}$ & $\begin{array}{c}\text { Neural } \\
\text { Networks } \\
\text { Based } \\
\text { Techniques } \\
\\
{[28-33]}\end{array}$ & $\begin{array}{c}\begin{array}{c}\text { Satellite } \\
\text { Based } \\
\text { Techniques }\end{array} \\
\text { [34-37] }\end{array}$ & $\begin{array}{c}\begin{array}{c}\text { UAV/ Air } \\
\text { borne } \\
\text { Techniques }\end{array} \\
\text { [38-42] }\end{array}$ & $\begin{array}{c}\text { Fuzzy Logic } \\
\text { Based } \\
\text { Techniques } \\
{[43,44]}\end{array}$ & $\begin{array}{c}\begin{array}{c}\text { Animals as } \\
\text { mobile } \\
\text { sensors }\end{array} \\
{[3,45]}\end{array}$ & $\begin{array}{c}\begin{array}{c}\text { Radio- } \\
\text { acoustic } \\
\text { based } \\
\text { techniques }\end{array} \\
{[46]}\end{array}$ \\
\hline Cost & Low & High & Low & Very High & High & Low & High & Medium \\
\hline Practicality & High & Medium & Low & Very High & High & Low & Very Low & Very Low \\
\hline $\begin{array}{c}\text { Frequency of } \\
\text { use in } \\
\text { literature }\end{array}$ & High & Medium & Rare & Very High & Medium & Rare & Very Rare & Very Rare \\
\hline $\begin{array}{l}\text { Detection } \\
\text { device } \\
\text { mobility }\end{array}$ & Fixed & Fixed & $\begin{array}{c}\text { Fixed or } \\
\text { mobile }\end{array}$ & Mobile & Mobile & $\begin{array}{c}\text { Fixed or } \\
\text { mobile }\end{array}$ & Mobile & Fixed \\
\hline $\begin{array}{l}\text { Battery } \\
\text { power } \\
\text { provided } \\
\text { through }\end{array}$ & $\begin{array}{l}\text { Rechargeable } \\
\text { Devices }\end{array}$ & $\begin{array}{c}\text { Rechargeable } \\
\text { Devices }\end{array}$ & $\begin{array}{l}\text { Rechargeable } \\
\text { Devices }\end{array}$ & Solar & $\begin{array}{c}\text { Rechargeable } \\
\text { Devices }\end{array}$ & $\begin{array}{c}\text { Rechargeable } \\
\text { Devices }\end{array}$ & $\begin{array}{c}\text { Rechargeable } \\
\text { Devices }\end{array}$ & $\begin{array}{c}\text { Rechargeable } \\
\text { Devices }\end{array}$ \\
\hline Information & Yes & No & Yes & Yes & Yes & Yes & Yes & No \\
\hline
\end{tabular}




\begin{tabular}{|c|c|c|c|c|c|c|c|c|}
\hline $\begin{array}{c}\text { on fire } \\
\text { behaviour }\end{array}$ & & & & & & & & \\
\hline $\begin{array}{l}\text { Region of } \\
\text { Interest }\end{array}$ & $\begin{array}{c}\text { Can be } \\
\text { extended }\end{array}$ & Limited & Limited & $\begin{array}{l}\text { Complete } \\
\text { Forest }\end{array}$ & $\begin{array}{c}\text { Can be } \\
\text { extended }\end{array}$ & Limited & Limited & $\overline{\text { Limited }}$ \\
\hline $\begin{array}{c}\text { Detection to } \\
\text { notification } \\
\text { delay }\end{array}$ & Small & Long & Small & Very Long & Long & Small & Long & Small \\
\hline False Alarm & Low & Medium & Medium & Very Low & Medium & Medium & High & High \\
\hline $\begin{array}{c}\text { Fire } \\
\text { localization } \\
\text { error }\end{array}$ & Low & High & Low & Very High & High & Low & High & High \\
\hline
\end{tabular}

Table 2: Year Wise and Category Wise References used in this Article

\begin{tabular}{|c|c|c|c|c|c|}
\hline Year $\Longrightarrow$ & 2008-10 & 2011-13 & 2014-16 & 2017-18 & Total References \\
\hline WSN Based & 4 & 4 & 1 & 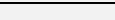 & 8 \\
\hline Camera Based & 5 & 2 & 5 & 3 & 15 \\
\hline Neural Networks Based & 2 & 1 & 2 & 1 & 6 \\
\hline Satellite Based & -- & -- & 4 & 1 & 5 \\
\hline UAV Based & 1 & 1 & 3 & -- & 5 \\
\hline Fuzzy Logic Based & & 1 & 1 & -- & 2 \\
\hline Animals as mobile sensors & 1 & -- & 1 & -- & 2 \\
\hline Radio-acoustic system & 1 & -- & -- & -- & 1 \\
\hline Total References & 14 & 9 & 17 & 5 & 45 \\
\hline
\end{tabular}

\section{Architecture of Basic Detection System}

This section describes the architecture of a basic fire detection system that can be thought of close to practical system using any one of the techniques. Fig 3a describes the architecture of system which can be implemented for fire detection if the region of interest for detection is limited. Example of limited region of interest may be a village in the middle of a forest or a building surrounded by dense trees. In such case a k-barrier coverage technique as discussed in [47]. In this fire is treated as an intrusion between two fixed points and nodes will be placed on points which are orthogonal to it. Barriers will be formed between these two nodes as shown in the figure. If any intrusion happens from any one of the fixed points, then it can be detected by the barrier network. The nodes placed on the orthogonal points are called as virtual nodes and the path established between these two virtual nodes will be a result communication between physically existing nodes along the paths.

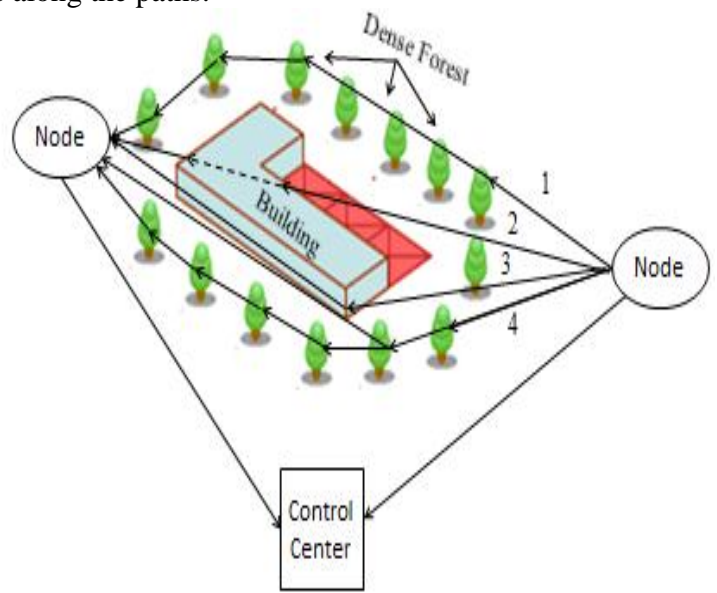

(a) Detection of fire in Limited Region of Interest
Fig $3 \mathrm{~b}$ describes an architecture of system that can detect incidences of fire in the complete forest. It is basically a cluster based network where a group of sensor node form a cluster and a central node will act as a cluster head. Sensor node will have limited range communication ability where as a cluster head i.e., central node can communicate directly with the control centre which can be either situated near to the forest under surveillance or it can also be situated remotely very far from the forest under surveillance.

The system proposed in the Fig. $3 \mathrm{a}$ and $3 \mathrm{~b}$ consists of sensor nodes which can have

i) Sensors such as temperature, humidity, $\mathrm{CO}$ which are suitable for fire detection through Wireless Sensor Networks

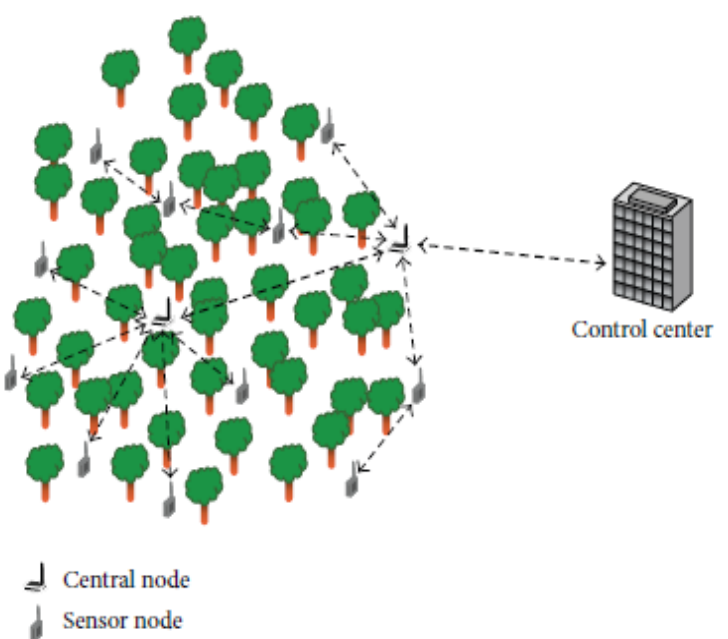

(b) Detection of fire in complete forest

Fig. 2: Proposed architectures of forest fire detection 
Table 3: List of sensors with potential applications

\begin{tabular}{|c|c|}
\hline Type of Sensor & Potential Applications \\
\hline Temperature sensor & $\begin{array}{c}\text { Detecting change in temperature with } \\
\text { respect to change in humidity }\end{array}$ \\
\hline Humidity sensor & $\begin{array}{c}\text { Detecting change in humidity with } \\
\text { respect to change in temperature } \\
\text { Detecting presence of smoke which } \\
\text { typically indicates occurrence of fire }\end{array}$ \\
\hline Carbon Monoxide(CO) sensor & Detecting CO gas released from fire \\
\hline Infra-red(IR) sensor & IR sensor is used as a flame indicator \\
\hline $\begin{array}{c}\text { Barometric Pressure sensor } \\
\text { Passive Microwave Imaging } \\
\text { sensor }\end{array}$ & $\begin{array}{c}\text { Detect the change in pressure in } \\
\text { environment in case of fire }\end{array}$ \\
\hline
\end{tabular}

ii) Cameras interfaced with sensor nodes such that image processing and video processing techniques can be implemented iii) Microprocessor and microcontroller along with sensor nodes to implement neural network and fuzzy logic based detection techniques.

iv) Unmanned Aerial Vehicle (UAV) embedded with sensors that can detect and monitor the incidences of fire.

v) Sensors as wearable devices capable of detecting fire incident and which can be placed on inhabitants of forest.

Communication between central node and sensor nodes can be through ZigBee transceiver, Radio Frequency transceiver, GSM transceiver through SMS. Likewise, communication between central node and control centre can be through ZigBee transceiver, Radio Frequency transceiver, GSM transceiver or else Internet of Things concept can be utilized. GSM communication allows a user to send alerts in the form of SMS (Short Message Service) or in the form of call to the firefighting services so that the rescue operations can be immediately carried without any delay. A ZigBee communication is desirable in scenarios where the amount of hardware required is limited and also the cost function is of prime importance.

\section{Conclusion}

In this article a details review of techniques available for forest fire detection from the literature has been performed with respect to generalized parameters that fits best to all the techniques. Finally, we propose a list of sensors that can be used in any technique and are readily available. Table III gives the list of sensors that can be used for forest fire detection with their potential applications. Out of the listed sensors one can easily conclude that the frequently used sensors for forest fire detection are temperature humidity smoke and $\mathrm{CO}$ sensor. The other sensors can be combined with aforementioned sensors in order to reduce the rate of false alarms and increase the detection probability. The similarity index of measurements among different sensors should be carried out in order to make sure that the combinations of sensors will not give false alarms. For example, when temperature, humidity and smoke sensors are used together than one can compare the readings of temperature with humidity and smoke so that false alarms can be reduced to negligible count. When fire occurs temperature increases and humidity decreases therefore combination reading reduces the rate of false alarms. Moreover, the network for forest fire detection should be an easy to implement network with a very little or no maintenance.

\section{References}

[1] Alkhatib, A.A., A review on forest fire detection techniques. International Journal of Distributed Sensor Networks, 2014. 10(3): p. 597368.

[2] Chowdary, V. and M.K. Gupta, Automatic Forest Fire Detection and Monitoring Techniques: A Survey, in Intelligen Communication, Control and Devices2018, Springer. p. 1111-1117.

[3] Sahin, Y.G., Animals as mobile biological sensors for forest fire detection. Sensors, 2007. 7(12): p. 3084-3099.
[4] Bouabdellah, K., H. Noureddine, and S. Larbi, Using wireless sensor networks for reliable forest fires detection. Procedia Computer Science, 2013. 19: p. 794-801.

[5] Díaz-Ramírez, A., et al., Wireless sensor networks and fusion information methods for forest fire detection. Procedia Technology, 2012. 3: p. 69-79.

[6] Aslan, Y.E., I. Korpeoglu, and Ö. Ulusoy, A framework for use of wireless sensor networks in forest fire detection and monitoring. Computers, Environment and Urban Systems, 2012. 36(6): p. 614 625.

[7] Bayo, A., et al., Early detection and monitoring of forest fire with a wireless sensor network system. Procedia Engineering, 2010. 5: p. 248-251.

[8] Zervas, E., et al., Multisensor data fusion for fire detection. Information Fusion, 2011. 12(3): p. 150-159.

[9] Bhattacharjee, S., et al., Wireless sensor network-based fire detection, alarming, monitoring and prevention system for Bordand-Pillar coal mines. Journal of Systems and Software, 2012. 85(3): p. 571-581.

[10] Ulucinar, A.R., I. Korpeoglu, and A.E. Cetin, A Wi-Fi cluster based wireless sensor network application and deployment for wildfire detection. International Journal of Distributed Sensor Networks, 2014. 10(10): p. 651957.

[11] Kosucu, B., et al. FireSenseTB: A wireless sensor networks testbed for forest fire detection. in Proceedings of the 2009 International Conference on Wireless Communications and Mobile Computing: Connecting the World Wirelessly. 2009. ACM.

[12] Hefeeda, M. and M. Bagheri, Forest Fire Modeling and Early Detection using Wireless Sensor Networks. Ad Hoc \& Sensor Wireless Networks, 2009. 7(3-4): p. 169-224.

[13] Zhang, Q.-X., et al., Wildland Forest Fire Smoke Detection Based on Faster R-CNN using Synthetic Smoke Images. Procedia Engineering, 2018. 211: p. 441-446.

[14] Rao, G.N., et al., Fire detection in Kambalakonda Reserved Forest, Visakhapatnam, Andhra Pradesh, India: An Internet of Things Approach. Materials Today: Proceedings, 2018. 5(1): p. 1162-1168.

[15] Çetin, A.E., et al., Video fire detection-Review. Digital Signal Processing, 2013. 23(6): p. 1827-1843.

[16] Wong, A.K. and N. Fong, Experimental study of video fire detection and its applications. Procedia Engineering, 2014. 71: p. 316-327.

[17] Rosas-Romero, R., Remote detection of forest fires from video signals with classifiers based on K-SVD learned dictionaries. Engineering Applications of Artificial Intelligence, 2014. 33: p. 111.

[18] Rong, J., et al., Fire flame detection based on GICA and target tracking. Optics \& Laser Technology, 2013. 47: p. 283-291.

[19] Celik, T. and H. Demirel, Fire detection in video sequences using a generic color model. Fire Safety Journal, 2009. 44(2): p. 147-158.

[20] Chunyu, Y., et al., Video fire smoke detection using motion and color features. Fire technology, 2010. 46(3): p. 651-663.

[21] Günay, O., et al., Video based wildfire detection at night. Fire Safety Journal, 2009. 44(6): p. 860-868.

[22] Zhou, Z., et al., Wildfire smoke detection based on local extremal region segmentation and surveillance. Fire Safety Journal, 2016. 85: p. $50-58$

[23] Gubbi, J., S. Marusic, and M. Palaniswami, Smoke detection in video using wavelets and support vector machines. Fire Safety Journal, 2009. 44(8): p. 1110-1115.

[24] Millan-Garcia, L., et al., An early fire detection algorithm using IP cameras. Sensors, 2012. 12(5): p. 5670-5686.

[25] Khatami, A., et al., A new PSO-based approach to fire flame detection using K-Medoids clustering. Expert Systems with Applications, 2017. 68: p. 69-80.

[26] Hackner, A., et al., Heterogeneous sensor arrays: Merging cameras and gas sensors into innovative fire detection systems. Sensors and Actuators B: Chemical, 2016. 231: p. 497-505.

[27] Ko, B.C., K.-H. Cheong, and J.-Y. Nam, Fire detection based on vision sensor and support vector machines. Fire Safety Journal, 2009. 44(3): p. 322-329.

[28] Muhammad, K., J. Ahmad, and S.W. Baik, Early Fire Detection using Convolutional Neural Networks during Surveillance for Effective Disaster Management. Neurocomputing, 2017.

[29] Zhang, D., et al. Image based forest fire detection using dynamic characteristics with artificial neural networks. in Artificial Intelligence, 2009. JCAI'09. International Joint Conference on. 2009. IEEE. 
[30] Soliman, H., K. Sudan, and A. Mishra. A smart forest-fire early detection sensory system: Another approach of utilizing wireless sensor and neural networks. in Sensors, 2010 IEEE. 2010. IEEE.

[31] Kolesenkov, A., et al. Anthropogenic situation express monitoring on the base of the fuzzy neural networks. in Embedded Computing (MECO), 2014 3rd Mediterranean Conference on. 2014. IEEE.

[32] Chauhan, A., S. Semwal, and R. Chawhan. Artificial neural network-based forest fire detection system using wireless sensor network. in India Conference (INDICON), 2013 Annual IEEE. 2013. IEEE.

[33] Satir, O., S. Berberoglu, and C. Donmez, Mapping regional forest fire probability using artificial neural network model in a Mediterranean forest ecosystem. Geomatics, Natural Hazards and Risk, 2016. 7(5): p. 1645-1658.

[34] Filizzola, C., et al., RST-FIRES, an exportable algorithm for earlyfire detection and monitoring: Description, implementation, and field validation in the case of the MSG-SEVIRI sensor. Remote Sensing of Environment, 2017. 192: p. e2-e25.

[35] Coppo, P., Simulation of fire detection by infrared imagers from geostationary satellites. Remote Sensing of Environment, 2015 162: p. 84-98

[36] Koltunov, A., et al., The development and first validation of the GOES Early Fire Detection (GOES-EFD) algorithm. Remote Sensing of Environment, 2016. 184: p. 436-453.

[37] Oliva, P. and W. Schroeder, Assessment of VIIRS $375 \mathrm{~m}$ active fire detection product for direct burned area mapping. Remote Sensing of Environment, 2015. 160: p. 144-155.

[38] Krüll, W., et al., Early forest fire detection and verification using optical smoke, gas and microwave sensors. Procedia Engineering, 2012. 45: p. 584-594.

[39] Dennison, P.E. and D.A. Roberts, Daytime fire detection using airborne hyperspectral data. Remote Sensing of Environment, 2009. 113(8): p. 1646-1657.

[40] Allison, R.S., et al., Airborne optical and thermal remote sensing for wildfire detection and monitoring. Sensors, 2016. 16(8): p. 1310.

[41] Cruz, H., et al., Efficient forest fire detection index for application in unmanned aerial systems (UASs). Sensors, 2016. 16(6): p. 893.

[42] Tomkins, L., et al., Use of night vision goggles for aerial forest fire detection. International journal of wildland fire, 2014. 23(5): p. 678-685.

[43] Ko, B., J.-H. Jung, and J.-Y. Nam, Fire detection and 3D surface reconstruction based on stereoscopic pictures and probabilistic fuzzy logic. Fire Safety Journal, 2014. 68: p. 61-70.

[44] Bolourchi, P. and S. Uysal. Forest fire detection in wireless sensor network using fuzzy logic. in Computational Intelligence, Communication Systems and Networks (CICSyN), 2013 Fifth International Conference on. 2013. IEEE.

[45] Bousack, H., et al., Towards Improved Airborne Fire Detection Systems Using Beetle Inspired Infrared Detection and Fire Searching Strategies. Micromachines, 2015. 6(6): p. 718-746.

[46] Sahin, Y.G. and T. Ince, Early forest fire detection using radioacoustic sounding system. Sensors, 2009. 9(3): p. 1485-1498.

[47] Kumar, S., et al. Optimal sleep-wakeup algorithms for barriers of wireless sensors. in Broadband Communications, Networks and Systems, 2007. BROADNETS 2007. Fourth International Conference on. 2007. IEEE. 